\title{
Several threats to China's environment and biodiversity
}

Volume 2 Issue 6 - 2017

\section{Opinion}

Recently, Jining Chen, the former minister of Ministry of Environmental Protection of the People's Republic of China rightfully pointed out that with sustained national efforts China has made great progress in environmental and biodiversity protection, such as the forest coverage rate had increased from $16.55 \%$ in 2000 to $21.63 \%$ in 2013; the volume of sewage treatment in urban areas has increased from 52 million tons to 182 million tons per day in the past decade; the sulfur dioxide and nitrogen oxide emission in the country's power stations have been reduced by $48 \%$ and $26 \%$, respectively since $2005 .{ }^{1}$ We agree with that, but here we want to highlight several threats that probably worsen China's environmental and biodiversity protection.

First, the severe water contamination, air pollution, and land degradation caused by rapid industrialization, urbanization, and economic development bring huge risk to the China's environment and biodiversity. For example, more than $60 \%$ large lakes and half of the 197 monitored rivers of China were heavily contaminated by discharged waste water, ammonium nitrate, minerals and organic compounds, which cause serious damage to the biodiversity. ${ }^{2}$ The air quality of 71 cities out of the 74 key large cities monitored in China, failed to meet the air quality standard in $2013 .{ }^{3}$ Long-term exposure to air pollution is causing 500 million residents of Northern China to lose more than 5 years of life expectancy on average. ${ }^{4}$ The World Health Organization estimated that on current trends by 2030, respiratory diseases will kill more than 3 million Chinese people a year. ${ }^{5}$ Croplands in China suffered seriously degradation due to organic matter depletion, overuse chemical fertilizer, and wind and soil erosion. Nearly $20 \%$ of China's crops land has been polluted by heavy metals and pesticides. ${ }^{6}$ Additionally, more than 4 million hectares of high-quality crops land has been converted to urban use in recent decade. ${ }^{7}$ The earthworm population of China's croplands decreased sharply due to long-term chemical fertilizer and pesticide use. ${ }^{8}$ Second, climate change and poor environmental practice combined together has exacerbated the environment and biodiversity of China. In the arid and semi-arid northwestern China, the widely a forestation by planting monoculture plantations of non-native trees or shrubs has exacerbated the depletion of the groundwater resource and the ecosystem degradation. ${ }^{9}$ In the southwestern China, the more and more frequently occurred extreme weather combined with inefficient hydrological infrastructure seriously threatened the biodiversity of this region, which is a global biodiversity hotspot. ${ }^{10}$ In the Plateau of Tibet, the hotter and wetter weather combined with the more polluted environment are jeopardizing the fragile ecosystems and biodiversity of the plateau. ${ }^{11}$

Third, the giant dams constructed for hydroelectric exploitation, particularly the ones on upper Yangtze region in southwestern China, not only could trigger deadly earthquakes, ${ }^{12}$ but also pose huge risk to the biodiversity around this region. For example, the migratory fishes such as the Chinese sturgeon (Acipenser sinensis) decline sharply mainly due to they can't pass the dams to the upstream to

\author{
Hong-Wei Xiao,' AS Mujumdar² \\ 'College of Engineering, China Agricultural University, China \\ ${ }^{2}$ Department of Bioresource Engineering, McGill University, \\ Canada
}

Correspondence: AS Mujumdar, Department of Bioresource Engineering, McGill University, Ste. Anne de Bellevue, Quebec, Canada,Email xhwcaugxy@163.com

Received: August 23, 2017 | Published: September 12, 2017

spawn and the situation is worsening by pollution and overfishing. The Yangtze River Dolphin (Lipotes vexillifer), and the Chinese paddlefish (Psephurus gladius) are functionally extinct, the Jiangzhu (Neophocaena phocaenoides asiaorientalis) is at risk of extinction. ${ }^{13}$ The ecosystems at the upper Yangtze River are nearly at the brink of collapse and the fishery resources shrinks severely according to a joint comprehensive survey of the upper Yangtze River region carried out by the World Wide Fund for Nature and the Ministry of Agriculture of China in 2013. ${ }^{14}$

The fourth one is the disappearing wetlands due mainly to cropland reclamation, biological resources exploitation, and environmental pollution. Since 1950 s more than $57 \%$ of China's coastal wetlands have disappeared, particularly the mangrove forests have decreased by $73 \% .{ }^{15}$ The Yellow River delta the most extensive delta in China has shrank nearly half and more than $40 \%$ fishes and $30 \%$ bird species have disappeared since 1970s. ${ }^{16}$ In addition, the huge seawall construction in coastal wetlands poses serious risk to the biodiversity of China.${ }^{17}$ Fifth, as the blooming of international trade, transportation and travelling, more and more exotic species invade China and pose a significant risk to the environment and biodiversity through spreading fatal diseases or parasites, poisoning the native predators, destroying the natural habitat of native fauna, or competing with native species for limited nutrition. China is one of the countries, which are under the most serious suffering from the alien species. More than 540 alien species have invaded China and cause annual economic loss as high as $\$ 32.5$ billion. ${ }^{17}$ Half of the top- 100 most dangerous invasive species identified by the International Union for Conservation of Nature have widely spread in China, such as the notorious water hyacinth (Eichharnia crassipes), American moths (Hyphantria cunea), pine wood nematode (Bursaphelench xylophilus).

Just as Chinese President Xi Jinping pointed "Build a beautiful China and improve the ecological environment is to develop the productive forces. Protect the ecological environment like the eyes, treat the ecologcial environment like life. Green mountains and clean 
water are just as valuable as a mountain of gold and silver." Therefore, to mitigate these threatens and save biodiversity, China must drop its "growth-at-any-cost" and "pollution first and cleanup afterward" strategy, instead ecological civilization should be a priority for the sustainable development of China and the whole world. We believe that as the second largest economy in the world China has sufficient motivations, financial resources and confidence to achieve ecological civilization and sustainable development.

\section{Acknowledgments}

None.

\section{Conflicts of interest}

The authors declare there is no conflict of interests.

\section{Funding}

None.

\section{References}

1. Chen J. A bright future for sustainable development:ushered in by innovation. Engineering. 2016;2(1):16-18.

2. Fu B. Blue skies for China. Science. 2008;321(5889):611.

3. Xiao HW, Mujumdar AS, Che L. Pollution:uncouple from economy boom. Nature. 2015;517(7533):145.

4. Chen Y, Ebenstein A, Greenstone M, et al. Evidence on the impact of sustained exposure to air pollution on life expectancy from China's Huai River policy. Proceedings of the National Academy of Sciences of the United States of America. 2013;110(32):12936-12941.
5. Hughes V. Public health:where there's smoke. Nature. 2012;489(7417):S18-S20

6. Yang H. China must continue the momentum of green law. Nature. 2014;509(7502):535.

7. Kong X. China protect high-quality arable land. Nature. 2014;506(7486):7

8. Liu J, Diamond J. China's environment in a globalizing world. Nature. 2005;435(7046):1179-1186.

9. Xu J. China's new forests aren't as green as they seem:impressive reports of increased forest cover mask a focus on non-native tree crops that could damage the ecosystem. Nature. 2011;477(7365):371.

10. Shu SS, Jiang W, Whitten T, et al. Drought and China's cave species. Science. 2013;340(6130):272.

11. Qiu J. Double threat for Tibet. Nature. 2014;512(7514):240-241.

12. Qiu J. Chinese data hint at trigger for fatal quake. Nature. 2008;513(7515):154-155.

13. Stone R. Three Gorges Dam:into the unknown. Science. 2008;321(5889):628-632.

14. China environment news "The ecosystems at the upper Yangtze River are nearly at the brink of collapse" in Chinese. China

15. Qiu J. China faces up to 'terrible' state of its ecosystems. Nature. 2011;471(733):19.

16. The Beijing News "The quietly change of the Yellow River delta" in Chinese, China.

17. Ma Z, Melville DS, Liu J, et al. Rethinking China's new great wall. Science. 2014;346(6212):912-914. 